\title{
Associations between Justice Scores, Care Scores, General Negative Affect, and General Positive Affect and Gender of Undergraduate Students at Prince of Songkla University
}

\author{
Kasetchai Laeheem ${ }^{1} \&$ Kanda Janyam ${ }^{1}$ \\ ${ }^{1}$ Faculty of Liberal Arts, Prince of Songkla University, Hatyai, Thailand \\ Correspondence: Kasetchai Laeheem, Faculty of Liberal Arts, Prince of Songkla University, Hatyai, Songkhla, \\ 90110, Thailand. E-mail: Lkasetchai@yahoo.com
}

Received: July 31, 2014 Accepted: October 31, 2014 Online Published: February 12, 2015

doi:10.5539/ass.v11n5p10

URL: http://dx.doi.org/10.5539/ass.v11n5p10

\begin{abstract}
This study investigated the association between the justice scores, care scores, general negative affect, and general positive affect among male and female undergraduate students at Prince of Songkla University, Thailand. Data were collected from 2,668 participants who were selected by means of systematic random sampling technique and data analyses by calculating odds ratios and employing chi-square tests using the EcStat program. The results revealed that the justice scores, care scores, general negative affect, and general positive affect were statistically significant associations with gender of students $(p=.000)$. Male students were greater than female students had justice scores and general positive affect at a high level and moderate level. Meanwhile more male students had care scores and general negative affect with a low level than female students.
\end{abstract}

Keywords: justice scores, care scores, general negative affect, general positive affect, undergraduate students

\section{Introduction}

Currently, there is a lack of information that integrates emotional experience with moral theories. This study applies the above theories of moral orientation (justice and care) to David Watson's approach to understanding the role of affect in daily mood and temperament by investigating the types of affective experiences reported by adults with different moral orientations, as they engage in a moral decision-making task. This first step in integrating these theories involves assessment of moral orientation using an instrument that exemplifies theories of moral orientations Ethical Orientation Questionnaire (EOQ), along with simultaneous assessment for certain types of affect using an instrument that is based on Watson's model of affective experience. (Affective experience is defined as a state of being within which one consciously senses emotions and possibly becomes aware of a change in one's physiological state, all in response to some environmental or intrapersonal stimulus. In this study, affect will be measured and quantified as subscale scores on the Positive and Negative Affect Schedule-Expanded Form (PANAS-X) (Watson \& Clark, 1994).

First and foremost, this research study is an attempt to address the lack of information integrating moral theory with the emotional experience of moral decision making. The primary reason for such an integration evolved out of one of the most valid criticisms of moral theories: the charge that enough time and attention were not devoted to other aspects of moral functioning, especially the affective experience of moral development. This criticism is in direct confrontation with Kohlberg's insistence that his theoretical and philosophical foundations honored the entirety of human moral experience. Furthermore, this criticism can be applied to the limited program of research by Rest and his colleagues, who openly recognized the need for more comprehensive research on other aspects of moral functioning. The second rationale for this research project involves generating research in adult moral development while accounting for affective variables in moral development. Some psychologists suggest that the interaction of cognitive and emotional experiences may actually promote the development of both (Hoffman, 2000). Could this phenomenon also be true of moral development, since it has been theoretically related to cognitive development? If emotions are a powerful part of the experience of moral judgment, as Kohlberg (1974) and the Neo-Kohlbergians (Rest, 1986; Rest \& Narvaez, 1994; Rest, Narvaez, Bebeau, \& Thomas, 1999) suggest, could affective experience be more than just an ancillary phenomenon that does not impact the actual decision-making process? 
Instead of viewing emotional experience as an extra variable in the relationship between cognition and moral judgment, this study is an exploration of the types of emotions experienced as adults make moral judgments. This perspective acknowledges the complexity of adult moral reasoning while adding to the body of research on more advanced Kohlbergian and Neo-Kohlbergian levels of moral development. This study is an initial attempt to better understand how two important aspects of human experience, cognition and affect, come together in the moral domain. As Gilligan, Murphy, and Tappan (1990) once wrote about the problems inherent in being overzealous about continuing to separate and isolate aspects of human moral functioning, reason must be reunited with relationship, thereby making feelings an inseparable part of human thought. Watson (2000) studied affective experience by focusing on mood, which is an episode of varying length during which a person experiences multiple emotions that seem to follow certain cyclical patterns. He and his colleagues developed a hierarchical, two dimensional model of affect based on their research results (Tellegen, Watson, \& Clark, 1999; Watson, 2000; Watson, Clark, \& Tellegen, 1988). Watson and Clark (1994) also developed a model for understanding the complexity of affective experiences. In addition to his interest in short-term mood states, Watson also found that people tend to experience mood states that are stable over time; he called this phenomenon trait affect, and he has investigated this construct extensively. Watson distinguishes trait affect from another of his constructs, temperament, which is a long-term affective pattern that is related to various enduring aspects of personality. In general, Watson's approach provides a theoretically based, yet empirically supported view of how short-term, trait-based, and temperament-based affective experiences seem to center around two basic dimensions, Positive Affect and Negative Affect. In considering the above theories as well as the growing trends in emotion theory, Watson (2000) developed five basic assumptions that drive his theory of affect. His first assumption was that subjective mood states are the primary phenomenon of interest in his theory. In part, he was responding to the abundance of theory and research on the links between cognition and affect, like the work of Lazarus (1999), and Ortny, Clore, and Collins (1988). Even though behavior, cognition, and facial expressions are important parts of human experience that should be studied, Watson wanted to limit his attention to the conscious, subjective experience of feelings. He acknowledged several limitations in the way subjective mood states are measured, primarily the problems of relying on self-report instruments like his own PANAS-X. He suggested that certain experimental designs could reduce the threats to validity and reliability that self-report instruments usually carry. Watson's (2000) second assumption echoed the psychophysiological and neurological traditions of James and Cannon, respectively. He believed that moods and emotions are components of overarching biobehavioral systems that include affective, cognitive, biological, and behavioral components. Each component constantly interacts with the others. There is much debate on which of these components is the first to respond to environmental stimuli. For example, Lazarus (2000) insisted that cognition precedes affect, while Zajonc $(1980 ; 1984)$ argued that affective responses precede cognitive interpretations of stimuli. Instead of assuming that one or another goes first, Watson believes that all these systems respond to the environment synchronously in a complex series of feedback loops called biobehavioral systems. Watson cited several authors who have completed neuropsychological research supporting the idea of such systems. This type of research has spawned a model of interacting biobehavioral systems that explain human functioning in terms of systems that inhibit or activate cognitive, affective, behavioral, and biological functioning (e.g., Behavioral Inhibition System, Behavioral Activation System). Watson had great confidence in this systemic model. Watson's (2000) third assumption flows naturally from the second. When one component of a biobehavioral system is altered in some way, all the other components must change as well. The components act both as causes and effects. Even though several modern theories state that cognitions precedes affective experience, Watson takes care in noting that moods are not simply effects. They are also important causal variables that can motivate and direct behavior, produce systematic changes in thoughts and attitudes, and so on. The fourth assumption that Watson makes is that the biobehavioral systems which regulate mood are the product of natural selection, as Darwin proposed long ago. Affect serves many important adaptive functions. Negative moods are unpleasant and reactive in that they accompany physiological arousal to dangerous stimuli. Thus, they promote survival by enabling us to avoid situations that may harm or kill us. Positive moods motivate us to approach environmental stimuli, maintain higher energy levels, and acquire resources that may enhance survival. Watson gives the example of how humans find pleasure in food, warmth, shelter, cooperation with others, and sexual experiences, all of which are essential to survival. Finally, Watson (2000) relies on the results of his extensive PANAS-X research base to inform his fifth assumption. He wrote that positive affect (PA) and negative affect (NA) coexist, but they operate independently of each other, and should be treated as two separate concepts. Watson gives the example of how someone could feel the negative affect of being anxious along with the positive affect of feeling excited, like when trying a new activity. He explains that NA and PA always coexist at low intensity levels in the stream of affect (to be discussed later), which is like a baseline state of functioning. He also explains that NA is part of a 
Behavioral Inhibition System, and PA is part of a Behavioral Activation System (both mentioned earlier), thus they operate in separate dimensions of human functioning.

An ethic of justice is based on abstract, impersonal principles, fairness, and equality. People with this style tend to place a good deal of weight on moral principles and laws, which they believe should be applied to all equally, and try to be objective and fair, hoping to make a decision according to some standard that's "higher" than any specific individual's interests (Kohlberg, 1974; Rest \& Narvaez, 1994). This style is more common of men than women, and of people who define themselves in more solitary and individualistic terms. It seems to fit with a more legalistic approach to life that gives allegiance to some external source of authority. This approach can also go along with a traditional management style that prefers to justify decisions according to authority, policies or other impersonal standards (Noddings, 2003). For these people, moral dilemmas generally involve a conflict of duties or responsibilities. People with this orientation believe that the focal point of every ethical dilemma is the specific individuals involved and the particular circumstances of the case. Solutions, then, must be tailored to the special details of individual circumstances. Notions of equity, or what is appropriate or "fitting," tend to be favored by this approach. Their reliance on subjective, "gut" response can limit their appreciation of other factors. When carried to an extreme, this style can produce decisions that seem not simply subjective, but arbitrary. This style is more common of women than men, and of people who define themselves primarily in terms of their relationships with other people (Slote, 2004; Held, 2005). Whereas, Gilligan (1982) offered that a morality of care can serve in the place of the morality of justice and rights. The morality of caring and responsibility is premised in nonviolence, while the morality of justice and rights is based on equality. Another way to look at these differences is to view these two moralities as providing two distinct injunctions - the injunction not to treat others unfairly (justice) and the injunction not to turn away from someone in need (care). She presents these moralities as distinct, although potentially connected.

Based on the circumstances and problems outlined above, this study was conducted to investigate the association between the justice scores, care scores, general negative affect, and general positive affect among male and female undergraduate students at Prince of Songkla University, Thailand. The results of this study would be useful for all related parties to utilize in preventing and increasing for undergraduate students who had low of justice scores, care scores, general negative affect, and general positive affect before the problem becomes more severe and turns into social problems in addition to helping each other to timely solve the problem.

\section{Objective}

To investigate the association between the justice scores, care scores, general negative affect, and general positive affect among male and female undergraduate students at Prince of Songkla University, Thailand.

\section{Methods}

\subsection{Subject Group}

The subjects of this study were 2,668 undergraduate students at Prince of Songkla University, Thailand studying in academic year 2011. On the predefined sample of students (the sample size was determined by Yamane formula at $\mathrm{p}=.018$ ) that was being representative and unified with the student population investigated in Prince of Songkla University. The sample was selected by means of systematic random sampling technique form database of Registrar's Division, Prince of Songkla University.

\subsection{Research Instruments}

The nature of this research is quantitative. Standardized PANAS X and EOQ (Questionnaire of ethical orientation) were used, and understood clearly since they were drawn up in Thai.

PANAS X (Positive and Negative Affect Schedule Expanded Form): It is longer than its original form for the purpose of assessing more discrete, hierarchical dimensions of PA and NA that are proposed in the two-factor model of affect. The resulting instrument follows the same format as the original PANAS, but it contains 60 items to be rated by respondents. The items correspond with 13 scales, including the General Dimension scales of PA and NA, and the Basic Negative Emotions scales of Fear, Hostility, Guilt, and Sadness. The Basic Positive Emotion scales consist of Joviality, Self-Assurance, and Attentiveness, while Other Affective scales measure Shyness, Fatigue, Serenity, and Surprise (Watson \& Clark, 1994). The respondents were required to rate the scale of their feeling from $5=$ extremely, $4=$ quite a bit, $3=$ moderately, $2=$ a little, $1=$ not at all.

EOQ (Ethical Orientation Questionnaire): The questionnaire consists of 9 hypothetical situations explained to examinees. For each hypothetical situation, two possible solutions were given - a sort of ethical dilemma. The scores on questionnaire show how strongly subjects prefer one or another of two major styles for recognizing and resolving ethical dilemmas. The scores show how strongly subjects prefer one or another of two major styles 
for recognizing and resolving ethical dilemmas. The higher subjects " $\mathrm{J}$ " score, the more subjects rely on an "ethic of justice". The higher subjects "C" score, the more they prefer an "ethic of care".

To create the standard Thai and Serbian version of the research instrument, the standard procedure of instrument translation (backward translation) was employed. That is, each questionnaire was first translated from English to Thai and Serbian and then from Thai and Serbian to English to ensure translation quality and adequate use of them. The instrument was administered to 30 undergraduate students to test the internal consistency and validity. Discrimination test was conducted by using t-test, it was found that all items the lower and upper group were significantly difference. To test the reliability of the questionnaire, the internal consistency of the question items was tested. Both the reliability and validity were good and the internal consistency has the Cronbach alpha coefficient values of $0.873-0.878$.

Then, the average scores of the justice scores, care scores, general negative affect, and general positive affect were then converted into $Z$-scores (mean $=0$, standard deviation: 1 ). The participants were then divided into three groups; those participants with a $Z$-score of less than $-1.0(Z<-1.0)$ were identified as having a low level group; those who had a $Z$ - score between -1.0 and $1.0(-1.0 \leq Z<-1.0)$ were classified as having a moderate level group; while those with a $Z$-score greater than $1.0(Z>1.0)$ were classified as having a high level group (Ender, 2005; Laeheem, 2013).

\subsection{Data Collection and Data Analysis}

The research data were collected by the researcher and experienced research assistants who were all graduate students. The questionnaire items were explained to the research assistants who were trained on how to collect the field data. The data obtained were expressed as frequencies and percentages, chi-square tests performed and odds ratios were derived using the EcStat statistical program.

\section{Results}

In this study, there were four dependent variables; justice scores, care scores, general negative affect, and general positive affect which has been divided into three categories; the group with low level, the group with moderate level, and the group with high level. There were 36.1 percent of the students had moderate level of justice scores, 34.5 percent with low level of justice scores and 29.4 percent with high level of justice scores. In addition, 43.6 percent of the students had moderate care scores, 28.5 percent with high care scores and 27.9 percent with low care scores. Meanwhile, in the area of general negative affect, 39.2 percent of the students had moderate level of general negative affect, 32.9 percent with low level of general negative affect and 27.9 percent showed high level of general negative affect. Moreover, 47.4 percent of the students had been general positive affect with a moderate level, 26.7 percent with a high level, and 25.9 percent had been general positive affect with a low level.

While the major independent variable in this study is a gender of students, based on the study group of 2,668 undergraduate students in this study; it was found that 71.7 percent are female.

Table 1. The associations between justice scores, care scores, general negative affect, and general positive affect and gender

\begin{tabular}{|c|c|c|c|c|c|}
\hline \multirow[b]{2}{*}{ Outcome } & \multicolumn{3}{|c|}{ Gender } & \multirow[b]{2}{*}{ Chi-square } & \multirow[b]{2}{*}{$p$-value } \\
\hline & $\begin{array}{l}\text { Male } \\
(755)\end{array}$ & $\begin{array}{l}\text { Female } \\
(1,913)\end{array}$ & $\begin{array}{l}\text { Total } \\
(2,668) \\
\end{array}$ & & \\
\hline Justice scores & & & & $35.631 * * *$ & .000 \\
\hline Low & 26.0 & 37.9 & 34.5 & & \\
\hline Moderate & 39.3 & 34.9 & 36.1 & & \\
\hline High & 34.7 & 27.2 & 29.4 & & \\
\hline Care scores & & & & $99.020 * * *$ & 0.000 \\
\hline Low & 41.6 & 22.5 & 27.9 & & \\
\hline Moderate & 36.8 & 46.3 & 43.6 & & \\
\hline High & 21.6 & 31.2 & 28.5 & & \\
\hline General negative affect & & & & $137.012 * * *$ & .000 \\
\hline Low & 49.5 & 26.4 & 32.9 & & \\
\hline Moderate & 32.5 & 41.8 & 39.2 & & \\
\hline High & 18.0 & 31.8 & 27.9 & & \\
\hline General positive affect & & & & $48.283^{* * *}$ & .000 \\
\hline Low & 16.8 & 29.5 & 25.9 & & \\
\hline Moderate & 51.0 & 46.0 & 47.4 & & \\
\hline High & 32.2 & 24.5 & 26.7 & & \\
\hline
\end{tabular}


Table 1 shows the result of the chi-square analysis assessing the associations between the justice scores, care scores, general negative affect, and general positive affect and gender. It was found that the justice scores, care scores, general negative affect, and general positive affect were statistically significant associations with gender of students $(p=.000)$ as illustrated in Table 1 .

Figures 1-4 shows the result of the odds ratio analysis assessing the plots of justice scores, care scores, general negative affect, and general positive affect by different gender, the results show that

Figure 1. Male students had justice scores at the high level at a ratio of 1.42 times $(95 \%$ confident interval $1.19-1.70)$ and at a moderate level at a ratio of 1.21 times (95\% confident interval 1.02-1.44) greater than female students.

Figure 2. Male students more often reported having care scores with a low level than did female students $(2.45$ times, 95\% confident interval 2.04-2.93).

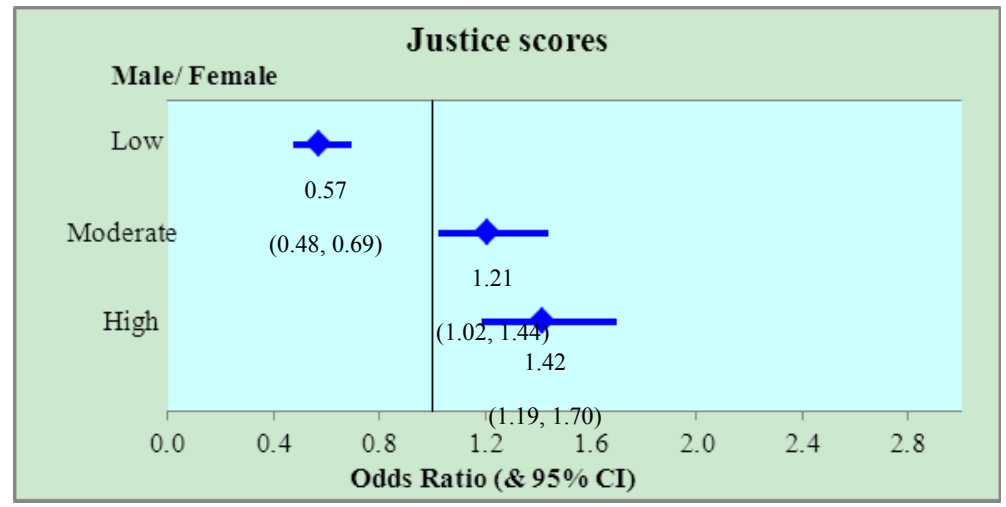

Figure 1. Odds ratio of justice scores by gender

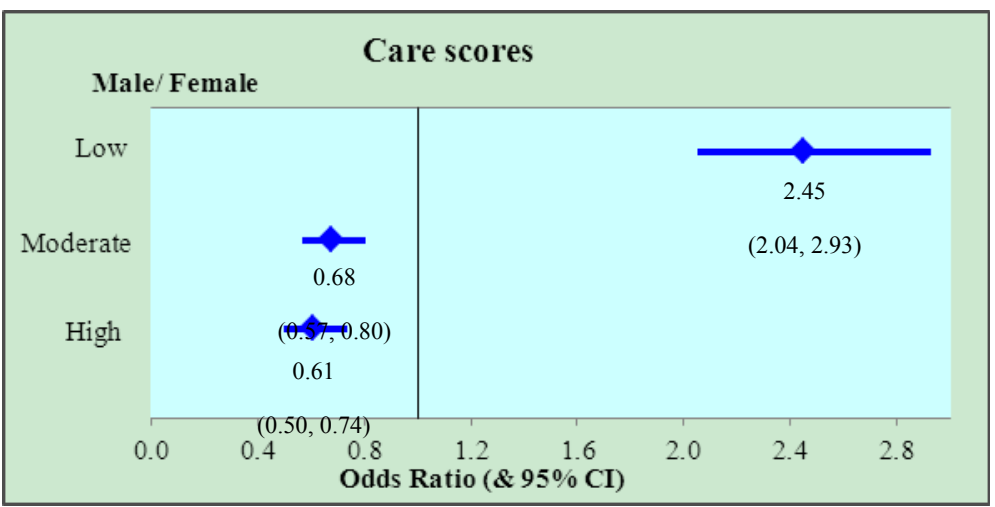

Figure 2. Odds ratio of care scores by gender

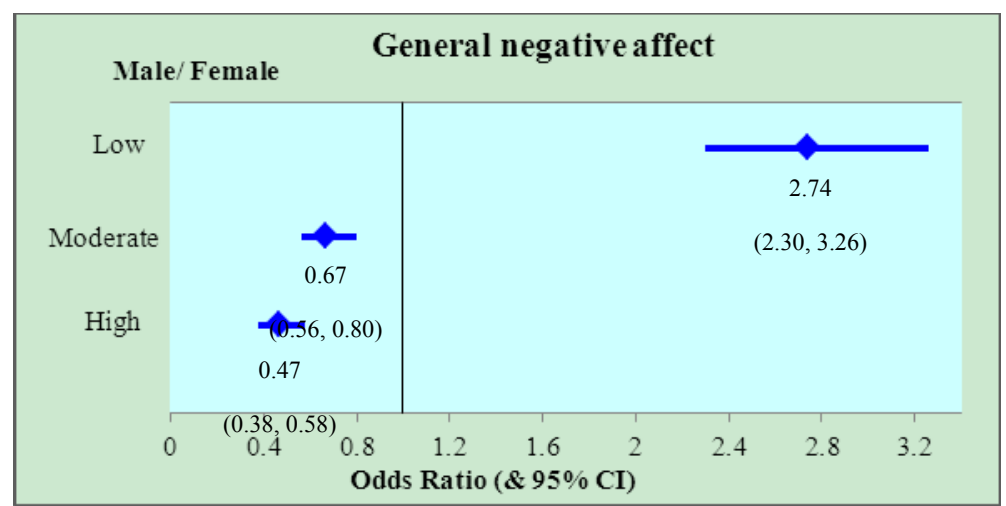

Figure 3. Odds ratio of general negative affect by gender 


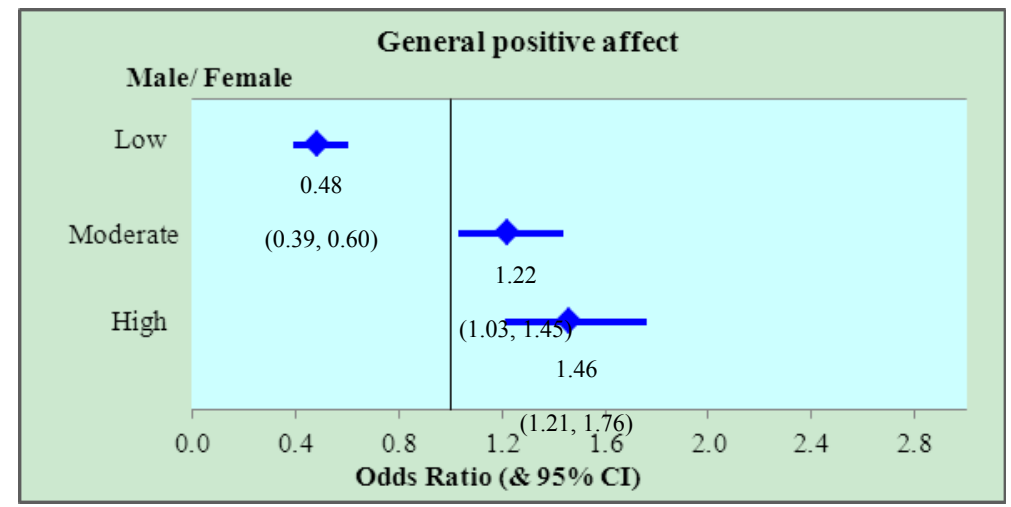

Figure 4. Odds ratio of general positive affect by gender

Figure 3. More male students than female students reported that they had a low level of general negative affect (2.74 times, 95\% confident interval 2.30-3.26).

Figure 4. Male students were more likely 1.46 times (confident interval 1.21-1.76) to have general positive affect at the high level and were more likely 1.22 times (confident interval 1.03-1.45) to have general positive affect at the moderate level than female students.

\section{Discussions and Conclusions}

The results indicated that male students had justice scores and general positive affect at both a high level and moderate level greater than female students. Meanwhile more male students had care scores and general negative affect with a low level than female students. Which is showed that male students had a higher score of justice and general positive affect than female students while female students had a higher score of care and general negative affect than male students.

The comparison between students of different gender revealed that male students' score of justice was higher than females' while females' score of care was higher than males'. The results were in accordance with previous studies indicating that males and females had different Ethical Orientation (Bampton \& Maclagan, 2009; Gilligan \& Attanucci, 1988). Female students had higher score of care and lower score of justice than male students. Women are more inclined than men to subscribe to an ethic of care and that once this perspective is adopted a pattern is discernable (Gilligan \& Attanucci, 1988). These findings can explain by socialization approach. The gender socialization approach argues that males and females have distinctive different values and traits due to gender creating different moral orientations and resulting in different decisions and practices (Kohlberg, 1973; 1974). Male and female to have a different moral orientation with women having a greater sense of commitment to doing things for other and men more pessimistic (Yankelovich, 1974). Females frame moral questions as problems of care, involving, empathy and compassion, while men frame moral questions as problems of justice rights and fairness (Gilligan, 1982). The female orientation as a "Care Orientation" while males are cited as having "Justice Orientation" (Langdale, 1983; Lyons, 1983).

However, when considering the factor of gender, male students had higher general positive affect and lower general negative affect average than female students. This might be because of social expectations in child rearing which is in Thai society to instil the gender role of a boy to be brave, strong and confident and to be a leader. As can be seen, males who have week character or lack confidence are less accepted than females who have that type of characteristics. This finding may explain by gender socialization that is process by which male students and female students learn the expectations associated with their sex. Gender socialization affects all aspects of daily life and society. It is reinforced whenever gender-linked behaviors receive approval or disapproval from family, peers, schooling, religious training, mass media, and popular culture are just a few of the agents through which gender socialization happens. These findings were in accordance with the study of Brody and Hall (1993) indicated that gender differences in emotions are adaptive for the differing roles that males and females play in their culture (Brody \& Hall, 1993). Men's roles are less likely to emphasize emotional responsiveness than women (Grossman \& Wood, 1993). Gender differences may be exaggerated as well, because women are more tied the biological processes that produce emotion, especially those having to do with birth, menstruation, and certain hormones (Brooks-Gunn \& Warren, 1989). The evidence for gender role differences can be found especially in work on socialisation. Research shows that male students are socialized to be more expressive of their feelings and to show this to a greater extent in facial expressions and gestures, as 
well as by verbal means (e.g. Walker-Andrews \& Haviland, 1994). Socialization occur s through parental practices (where mothers and fathers have both been found to express affect and use emotional words more towards male than female; e.g. Dunn, Bretherton, \& Munn, 1987; Malatesta, Culver, Tesman, \& Shepard, 1989), teacher and other authority and role-model interactions (e.g. Botkin \& Twardosz, 1988), and peer relations (where female are encouraged to avoid conflict, cooperate, and, in general, function in small, intimate groups; whereas male are rewarded for competing and for performing in hierarchical, status-oriented groups (Maltz \& Borker, 1982). All these forms of socialisation are, of course, reinforced by social norms, the media, and cultural forces to one degree or another. Finally, gender differences in the experience and expression of emotions are reinforced by one's emotional self-identity (Cross \& Madson, 1997; Eagly \& Wood, 1999).

In addition, the study found that male and female students had significantly different emotional condition; female students had higher general negative affect and lower general positive affect than male students. This shows that female students were more relaxed in expressing their emotion which could be because of the impact of the past experience the male students had - wars and struggle for independence - which might have become one factor both positively and negatively influencing the emotional condition and merged well within them. On the other hand, female students have not had such violent experience and besides, the Thai society is more relaxed in terms of culture, way of life and religious views which are mostly based on Buddhism. The way Thai people lead their life is influenced both directly and indirectly by the Buddha's teaching irrespective to the fact that they may or may not be Buddhists. Buddhism teaches human beings to live harmoniously, employing the principles of kindness and emphasizing the middle path as a way to lead a life; not focusing on one or the other too much to lose balance as can be seen in Phra Phromkunaphon's sermon (Payutto, 2006)

This lifestyle may have been an essential factor making Thai people easily adaptive to changes in the society and never take fast hold of any ideology. This is the factor that enables the Thais to lead a happy life happily and earn the name "The Land of Smile". The fact that Thai people live a happy life may not be a coincidence. Rather, it may result from the cultural structure and principles in living a life. This viewpoint may or may be true but it is an issue worth to be further studied.

The current study indicated that there is a statistically significant difference between male and female students population ethical orientation. In addition the results also revealed that there is a statistically significant difference between male and female students population in general negative affect and general positive affect. These results show us that we have to respect gender differences in process of moral education and also that moods (general negative affect and general positive affect) are association with ethical orientation. So our findings show us that we cannot discuss moral orientation only in cognitive terms. We have to adopt basic emotional traits (moods) as essential ingredients of our moral orientation and respect that fact in process of moral education.

\section{Acknowledgements}

This work was supported by Prince of Songkla University, I would like to thank for its financial support.

\section{References}

Bampton, R., \& Maclagan, P. (2009). Does a care orientation explain gender differences in ethical decision making? A critical analysis and fresh findings. Business Ethics: A European Review, 18(2), 179-191. http://dx.doi.org/10.1111/j.1467-8608.2009.01556.x

Botkin, D., \& Twardosz, S. (1988). Early childhood teachers' affectionate behavior: Differential expression to female children, male children, and group of children. Early Childhood Research Quarterly, 2, 167-177. http://dx.doi.org/10.1016/0885-2006(88)90020-8

Brody, L. R., \& Hall, J. (1993). Gender and emotion. In M. Lewis, \& J. Haviland (Eds.), Handbook of emotions (pp. 447-461). New York: Guilford Press.

Brooks-Gunn, J., \& Warren, M. P. (1989). Biological and social contributions to negative affect in young adolescent girls. Child Development, 60, 40-55. http://dx.doi.org/10.2307/1131069

Cross, S. E., \& Madson, L. (1997). Model of the self: Self-construal's and gender. Psychological Bulletin, 122, 5-37. http://dx.doi.org/10.1037/0033-2909.122.1.5

Dunn, J., Bretherton, I., \& Munn, P. (1987). Conversations about feeling states between mothers and their young children. Developmental Psychology, 23, 132-139. http://dx.doi.org/10.1037/0012-1649.23.1.132

Eagly, A. H., \& Wood, W. (1999). The origins of sex differences in human behavior: Evolved dispositions versus social roles. American Psychologist, 54, 408-423. http://dx.doi.org/10.1037/0003-066X.54.6.408 
Ender, P. (2005). Introduction to research design and statistics. Los Angeles: Department of Education

Gilligan, C. (1982). In a different voice: Psychological theory and women's development. Cambridge, MA: Harvard University Press.

Gilligan, C., \& Attanucci, J. (1988). Two moral orientations: Gender differences and similarities. Merrill-Palmer Quarterly, 34, 223-237.

Gilligan, C., Murphy, J. M., \& Tappan, M. (1990). Moral development beyond adolescence. In C. Alexander, \& E. Langer (Eds.), Higher stages of human development. New York: Oxford University Press.

Grossman, M., \& Wood, W. (1993). Gender differences in intensity of emotional experience: A social role interpretation. Journal of Personality and Social Psychology, 65, 1010-1022. http://dx.doi.org/10.1037/0022-3514.65.5.1010

Held, D. (2005). Principles of the cosmopolitan order. In G. Brock, \& H. Brighouse (Eds.), The Political Philosophy of Cosmopolitanism (pp. 10-27). Cambridge: Cambridge University Press. http://dx.doi.org/10.1017/CBO9780511614743.003

Hoffman, M. (2000). Empathy and moral development: Implications for caring and justice. Cambridge: Cambridge University Press. http://dx.doi.org/10.1017/CBO9780511805851

Kohlberg, L. (1973). The claim to moral adequacy of a highest stage of moral judgment. Journal of Philosophy, 70(18), 630-646. http://dx.doi.org/10.2307/2025030

Kohlberg, L. (1974). Education, moral development and faith. Journal of Moral Education, 4(1), 5-16. http://dx.doi.org/10.1080/0305724740040102

Laeheem, K. (2013). Needs for behavioral refinement based on Islamic principles among Muslim juveniles with risky types of behavior in three southern-border provinces of Thailand. Kasetsart Journal: Social Sciences, 34(1), 126-138.

Langdale, C. J. (1983) Moral orientations and moral development: The analysis of care and justice reasoning across different dilemmas in females and males from childhood through adulthood. Dissertation Abstracts International, 44, 1998B.

Lazarus, R. S. (1999). Hope: An emotion and a vital coping resource against despair. Social Research. 66, 653-678.

Lazarus, R. S. (2000). Towards better research on stress and coping. American Psychologist, 55(6), 665-673. http://dx.doi.org/10.1037/0003-066X.55.6.665

Lyons, N. P. (1983). Conceptions of self and morality and modes of moral choice: Identifying justice and care in judgments of actual moral dilemmas (Unpublished Doctoral's dissertation). Harvard University, Cambridge, MA.

Malatesta, C. Z., Culver, C., Tesman, J. R., \& Shepard, B. (1989). The development of emotion expression during the first two years of life. Monographs of the Society for Research in Child Development, 54, 1-104. http://dx.doi.org/10.2307/1166153

Maltz, D., \& Borker, R. (1982). A cultural approach to male-female miscommunication. In J. Gumperz (Ed.), Language and social identity (pp. 196-216). Cambridge: Cambridge University Press,

Noddings, N. (2003). Caring: A feminine approach to ethics and moral education. Berkeley, CA: University of California Press.

Ortony, A., Clore, G., \& Collins, A. (1988). The cognitive structure of emotions. Cambridge: Cambridge University Press. http://dx.doi.org/10.1017/CBO9780511571299

Payutto, P. A. (2006). A Constitution for Living. Bangkok: Sahathamika.

Rest, J. (1986). Moral development: Advances in research and theory. New York: Praeger.

Rest, J., \& Narvaez, D. (1994). Moral development in the professions: Psychology and applied ethics. Hillsdale, NJ: Lawrence Erlbaum.

Rest, J., Narvaez, D., Bebeau, M., \& Thoma, S. (1999). Postconventional moral thinking: A Neo-Kohlbergian Approach. Mahwah, New Jersey: Lawrence Erlbaum Associate.

Slote, M. (2004). Moral sentimentalism. Ethical Theory and Moral Practice, 7(1), 3-14. http://dx.doi.org/10.1023/B:ETTA.0000019982.56628.c3 
Tellegen, A., Watson, D., \& Clark, L. A. (1999). On the dimensional and hierarchical nature of affect. Psychological Science, 10, 297-303. http://dx.doi.org/10.1111/1467-9280.00157

Walker-Andrews, A. S., \& Haviland, J. N. (1994). Brief report: Preferential looking in intermodal perception by children with autism. Journal of Autism and Developmental Disorders, 4(1), 99-107. http://dx.doi.org/10.1007/BF02172216

Watson, D. (2000). Basic problems in positive mood regulation. Psychological Inquiry, 11, 205-209.

Watson, D., \& Clark, L. A. (1994). The PANAS-X Manual for the positive and negative affect schedule-expanded form. Iowa: The University of Iowa.

Watson, D., Clark, L. A., \& Tellegen, A. (1988). Development and validation of brief measures of positive and negative affect: The PANAS scales. Journal of Personality and Social Psychology, 54, 1063-1070. http://dx.doi.org/10.1037/0022-3514.54.6.1063

Yankelovich, D. (1974). The new morality. New York: McGraw Hill.

Zajonc, R. B. (1980). Feeling and thinking: Preferences need no inferences. American Psychologist, 35, 151-175. http://dx.doi.org/10.1037/0003-066X.35.2.151

Zajonc, R. B. (1984). On the primacy of affect. American Psychologist, 39, 117-123. http://dx.doi.org/10.1037/0003-066X.39.2.117

\section{Copyrights}

Copyright for this article is retained by the author(s), with first publication rights granted to the journal.

This is an open-access article distributed under the terms and conditions of the Creative Commons Attribution license (http://creativecommons.org/licenses/by/3.0/). 